\title{
CD133 expression associated with poor prognosis in ovarian cancer
}

\author{
Jing Zhang ${ }^{1,2,5}$, Xiaoqing Guo ${ }^{1,3,5}$, Doo Young Chang ${ }^{1,4}$, Daniel G Rosen ${ }^{1}$, \\ Imelda Mercado-Uribe ${ }^{1}$ and Jinsong Liu ${ }^{1}$ \\ ${ }^{1}$ Department of Pathology, The University of Texas MD Anderson Cancer Center, Houston, TX, USA; \\ ${ }^{2}$ Department of Pathology, Fourth Military Medical University, Shaanxi, China; ${ }^{3}$ Department of Gynecology \\ and Obstetrics, Shihezi University School of Medicine, Xinjiang, China and ${ }^{4}$ Department of Obstetrics \\ and Gynecology, Inje University Ilsan Paik Hospital, Gyeonggi-do, Korea
}

\begin{abstract}
As a putative marker for cancer stem cells in human malignant tumors, including ovarian cancer, CD133 expression may define a tumor-initiating subpopulation of cells and is associated with the clinical outcome of patients. However, at this time its clinical significance in ovarian cancer remains uncertain. The aim of this study was to clarify the clinical role of CD133 expression in human ovarian cancer. Immunohistochemical staining of CD133 expression was performed in 400 ovarian carcinoma samples using tissue microarray. The associations among CD133 expression and clinical factors (diagnosis, tumor grade, cancer stage, and clinical response to chemotherapy), overall survival and disease-free survival time were analyzed. CD133 expression was found in $31 \%$ of ovarian carcinoma samples. Fisher's exact test and one-way analysis of variance suggested that CD133 expression was associated with high-grade serous carcinoma $(P=0.035)$, late-stage disease $(P<0.001)$, ascites level $(P=0.010)$, and non-response to chemotherapy $(P=0.023)$. CD133 expression was also associated with shorter overall survival time $(P=0.007)$ and shorter disease-free survival time $(P<0.001)$ by log-rank test. Moreover, CD133 expression was an independent predictor of shorter disease-free survival time in an unconditional logistic regression analysis with multiple covariates $(P=0.024)$. Our results thus show that CD133 expression is a predictor of poor clinical outcome for patients with ovarian cancer, supporting the proposed link between CD133 and cancer stem cells.
\end{abstract}

Modern Pathology (2012) 25, 456-464; doi:10.1038/modpathol.2011.170; published online 11 November 2011

Keywords: CD133; immunohistochemistry; ovarian cancer; prognosis

Cancer has long been thought of as a molecularly heterogeneous population of cells, composed of diverse cell subpopulations with different proliferation capacities and differentiation potentials. However, recent evidence suggests that only a few cells within a tumor, known as cancer stem cells, have the capacity to initiate and sustain malignancy. ${ }^{1}$ In solid tumors, cancer stem cells have the capacity for selfrenewal and multipotent differentiation and the ability to induce tumorigenesis and resistance to chemotherapy or radiotherapy. ${ }^{2-4}$

Correspondence: Dr J Liu, MD, PhD, Department of Pathology, Unit 85, The University of Texas MD Anderson Cancer Center, 1515 Holcombe Boulevard, Houston, TX 77030, USA.

E-mail: jliu@mdanderson.org

${ }^{5}$ These authors contributed equally to this work.

Received 7 July 2011; revised 10 September 2011; accepted 12 September 2011; published online 11 November 2011
Ovarian cancer, the fifth leading cause of cancerrelated deaths among women in the United States, was estimated to affect over 21000 women and resulted in nearly 14000 deaths in $2010 .^{5}$ It is the most lethal gynecologic malignancy, primarily owing to the lack of a reliable early detection method, which results in most ovarian cancers being diagnosed at an advanced stage of disease. As in other malignant tumors, cancer stem cells in ovarian cancer are responsible for tumorigenesis and tumor growth. ${ }^{6}$

One potential marker for cancer stem cells in ovarian and other cancers is CD133, also known as Prominin-1, a five-transmembrane glycoprotein that has a molecular weight of $97 \mathrm{kDa}$ and is encoded by the PROM1 gene on chromosome $4 \mathrm{p} 15 .^{7,8}$ Although the function of CD133 is unclear, recent studies indicate that it is a marker of hematopoietic stem cells and progenitor cells ${ }^{9}$ and possibly one of the most reliable molecular markers for cancer stem 
cells in various solid tumors, including melanoma ${ }^{10}$ and brain, ${ }^{11}$ lung, ${ }^{12}$ liver, ${ }^{13}$ prostate, ${ }^{14}$ colon, ${ }^{15}$ breast, ${ }^{16}$ and ovarian cancers. ${ }^{17}$

As a putative marker for cancer stem cells in ovarian cancer, ${ }^{17,18}$ CD133 expression may define a tumor-initiating subpopulation of cells. Previous studies have shown that CD133-positive cells had more tumorigenic and aggressive capacity in vitro and/or in vivo compared with their CD133-negative progeny and that they exhibited increased resistance to chemotherapeutic strategies. ${ }^{17,19,20}$ Thus, CD133 expression may be associated with the clinical outcome of patients with ovarian cancer, but at this time its clinical significance remains uncertain. Therefore, we analyzed the association of CD133 expression in ovarian cancer with clinical factors, overall survival, and disease-free survival.

\section{Materials and methods}

\section{Patients and Clinicopathologic Data}

We analyzed ovarian carcinoma samples from 400 patients who were diagnosed with ovarian carcinoma and had undergone initial surgery at the University of Texas MD Anderson Cancer Center between 1 January 1990 and 22 February 2007, along with ovarian serous cystadenoma and normal ovarian and fallopian tube tissue samples. We obtained relevant clinical data on patients whose tissue samples we studied by retrospective review of the patients' files. These data included demographics, diagnosis, tumor grade, disease stage, ascites and serum cancer antigen 125 (CA125) level, chemotherapy regimen and response to chemotherapy. Follow-up information was updated through 31 March 2010, by reviewing medical records and the United States Social Security Index. The use of tissue blocks and the chart reviews were approved by the MD Anderson Institutional Review Board.

Histopathologic diagnoses were based on World Health Organization criteria. ${ }^{21}$ Tumor grade for nonserous carcinomas was assigned based on the Gynecologic Oncology Group criteria; ${ }^{22-24}$ serous carcinomas were graded on a two-tier system (lowgrade and high-grade) according to the criteria proposed by Malpica et $a l^{25}$ Disease staging was according to the International Federation of Gynecology and Obstetrics (FIGO) staging system. ${ }^{26}$

To analyze response to chemotherapy, we grouped patients as responders or non-responders. We defined responders as patients who entered complete clinical remission with a normal CA125 level after chemotherapy for histologically or cytologically diagnosed ovarian carcinoma and who had a treatment-free interval of $\geq 6$ months. ${ }^{27}$ Non-responder group included patients with progressive or recurrent disease. Progressive disease was defined as disease progression that occurred without any observed remission after the initiation of treatment; recurrent disease was defined as disease detected after a period of clinically documented remission of $<6$ months. ${ }^{28,29}$

\section{Immunohistochemical Analysis}

For this study, tissue microarray construction was performed as previously described. ${ }^{30}$ Tissue microarray slides were subjected to immunohistochemical staining according to the manufacturer's protocol (Biocare Medical, Concord, CA, USA). After sections were deparaffinized in xylene and rehydrated in graded alcohol dilutions, antigen retrieval was performed using a universal decloaker (UD1000M; Biocare Medical) in an autoclave at $121^{\circ} \mathrm{C}$ for $5 \mathrm{~min}$ to unmask the epitopes. Endogenous peroxidase activity was blocked using Peroxidazed 1 (PX968; Biocare Medical) at room temperature for $10 \mathrm{~min}$. Non-specific binding was blocked with Background Sniper (BS966M; Biocare Medical), with slides incubated for $15 \mathrm{~min}$ at room temperature. Next, the slides were incubated overnight at $4{ }^{\circ} \mathrm{C}$ with primary rabbit polyclonal antibody against CD133 (ab19898, 1:300 dilution; Abcam, Cambridge, MA, USA), then for $20 \mathrm{~min}$ with a biotin-labeled secondary antibody (Universal Goat Link, GU600H; Biocare Medical), and finally for $20 \mathrm{~min}$ with 4 plus HRP 1000 Universal (HP604; Biocare Medical). After being stained for $3 \mathrm{~min}$ with $\mathrm{DAB}$ Chromogen (DB801L; Biocare Medical), the tissues were counterstained with hematoxylin, dehydrated, and mounted. Negative controls were made by replacing the primary antibody with phosphate-buffered saline. One sample of human seminoma tissue was stained as a positive control. All controls yielded satisfactory results.

Two gynecologic pathologists (JL and JZ) independently analyzed the immunohistochemically stained slides for CD133 expression. Staining degree was scored, and the staining pattern-membrane and/or cytoplasmic reactivity of the cells-was noted. The degree of staining was quantified using a four-level grading system. Samples with no CD133-positive tumor cells were given a score of 0 ; those with $<5 \%$ CD133-positive tumor cells, 1 ; those with $5-50 \%$ CD133-positive tumor cells, 2 ; and those with $>50 \%$ CD133-positive tumor cells, 3. For statistical analysis, cases were divided into negative ( $\%$ CD133positive tumor cells; Figure 1e) or positive $(>0 \%$ CD133-positive tumor cells) CD133 expression.

\section{Statistical Analysis}

We used Fisher's exact test and logistic regression analysis to evaluate the association of CD133 expression with clinical factors. We performed one-way analysis of variance for multiple comparisons to evaluate the association of CD133 expression with response to chemotherapy. We used the Kaplan-Meier method to estimate overall survival and disease-free survival rates and the log-rank test 
to compare overall survival and disease-free survival time among different groups, such as patients with negative or positive CD133 expression. To adjust for the confounding effects of age at diagnosis, tumor grade, response to clinical treatment, and FIGO stage, we performed unconditional logistic regression analysis with multiple covariates in determining the association of CD133 expression with overall survival or disease-free survival.

Overall survival time was computed as the time interval from the date of first biopsy to the date of death from disease or the last follow-up date, whichever occurred first. Patients who were alive on the last follow-up date were censored from analysis. Disease-free survival time was computed as the time period from the date of first biopsy to the date of recurrence. Disease recurrence was determined clinically by the appearance of new lesions or an increase in the serum CA125 level to more than twice the upper limit of normal range (0-35 U/ $\mathrm{ml}){ }^{31,32}$ Patients alive without recurrence on the last follow-up date were censored from analysis. Results were considered statistically significant at the $P<0.05$ level. SPSS (version 17.0; SPSS, Chicago, IL, USA) and Stata (version 8.0; Stats Corporation, College Station, TX, USA) software were used for statistical analyses.

\section{Results}

\section{Patient Characteristics}

The mean age of the 400 patients we studied was 59 years (range, 20-89 years). At the time of this study, 67 patients were alive without clinical evidence of ovarian cancer, 53 were alive with ovarian cancer, 210 had died from ovarian cancer, 58 had died from unrelated or unknown ovarian cancer, and 12 were a

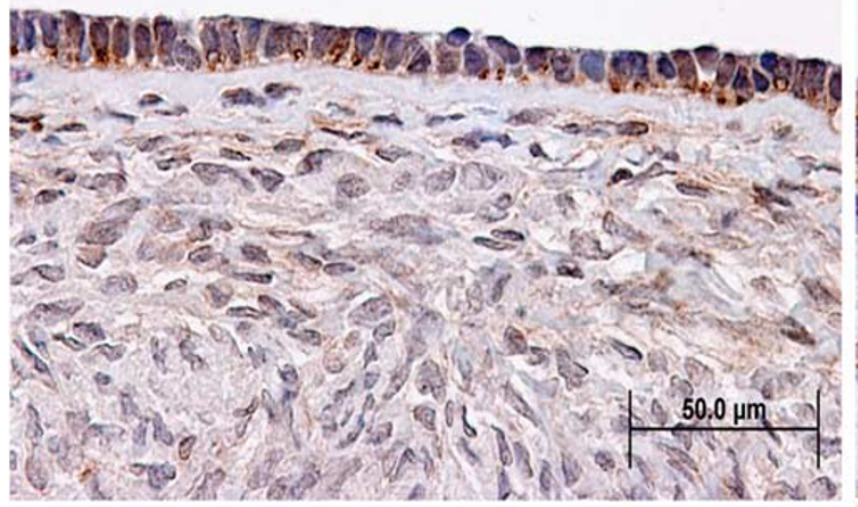

c

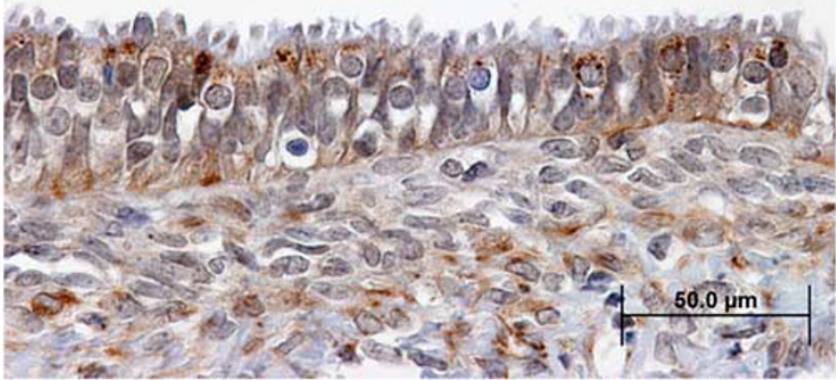

b

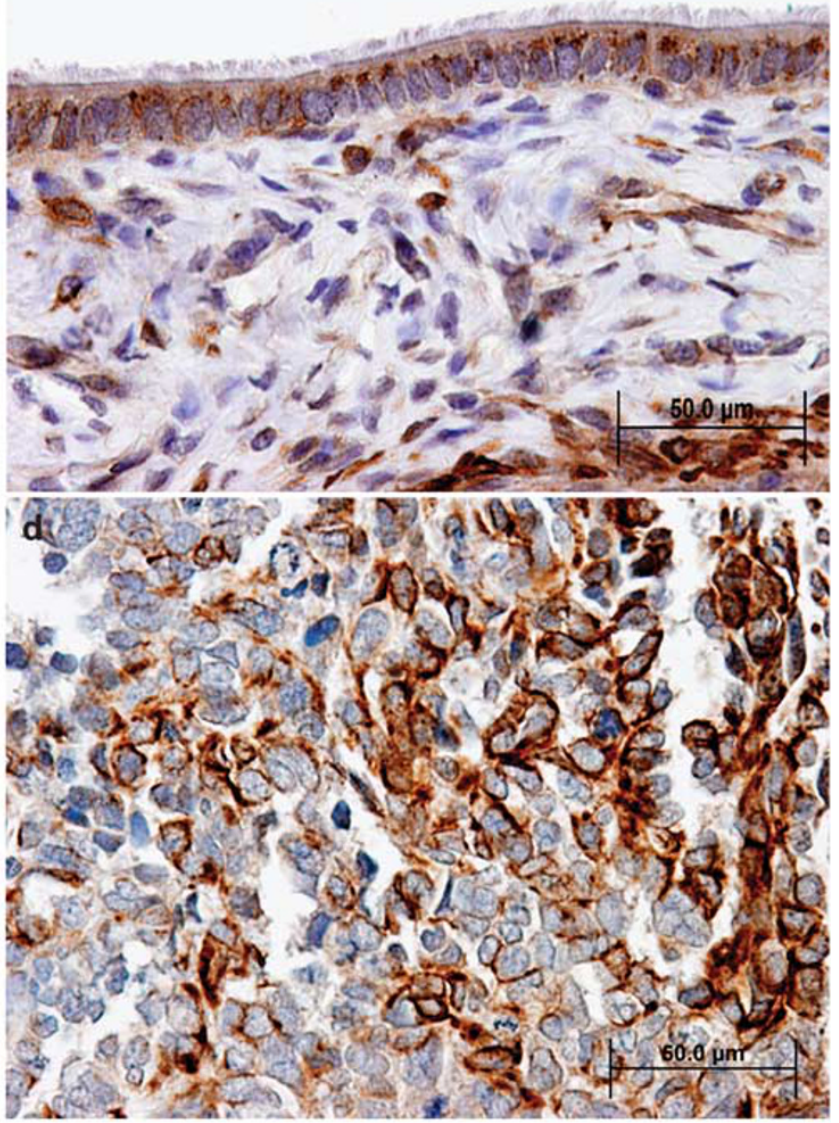

Figure 1 Pattern of CD133 immunoreactivity in normal ovarian, normal fallopian tube, ovarian serous cystadenoma, and ovarian carcinoma tissues. (a) CD133-positive staining in normal ovarian tissue. (b) Normal fallopian tube tissue showing a dot-like pattern of CD133 expression in the epithelial cells. (c) Serous cystadenoma tissue with a few cells showing a dot-like pattern of CD133 expression. (d) Cell membrane expression of CD133 in low-grade serous carcinoma. (e) Negative expression of CD133 in high-grade serous carcinoma. (f) The cytoplasmic expression of CD133 in high-grade serous carcinoma. (g) High-grade endometrioid adenocarcinoma cells showing CD133 expression diffusely in the cytoplasm. (h) Sparsely cytoplasmic staining for CD133 in malignant mixed müllerian tumor cells. $(\mathbf{a}-\mathbf{h})$ Original magnification $\times 400$; see text for immunostaining procedure. 

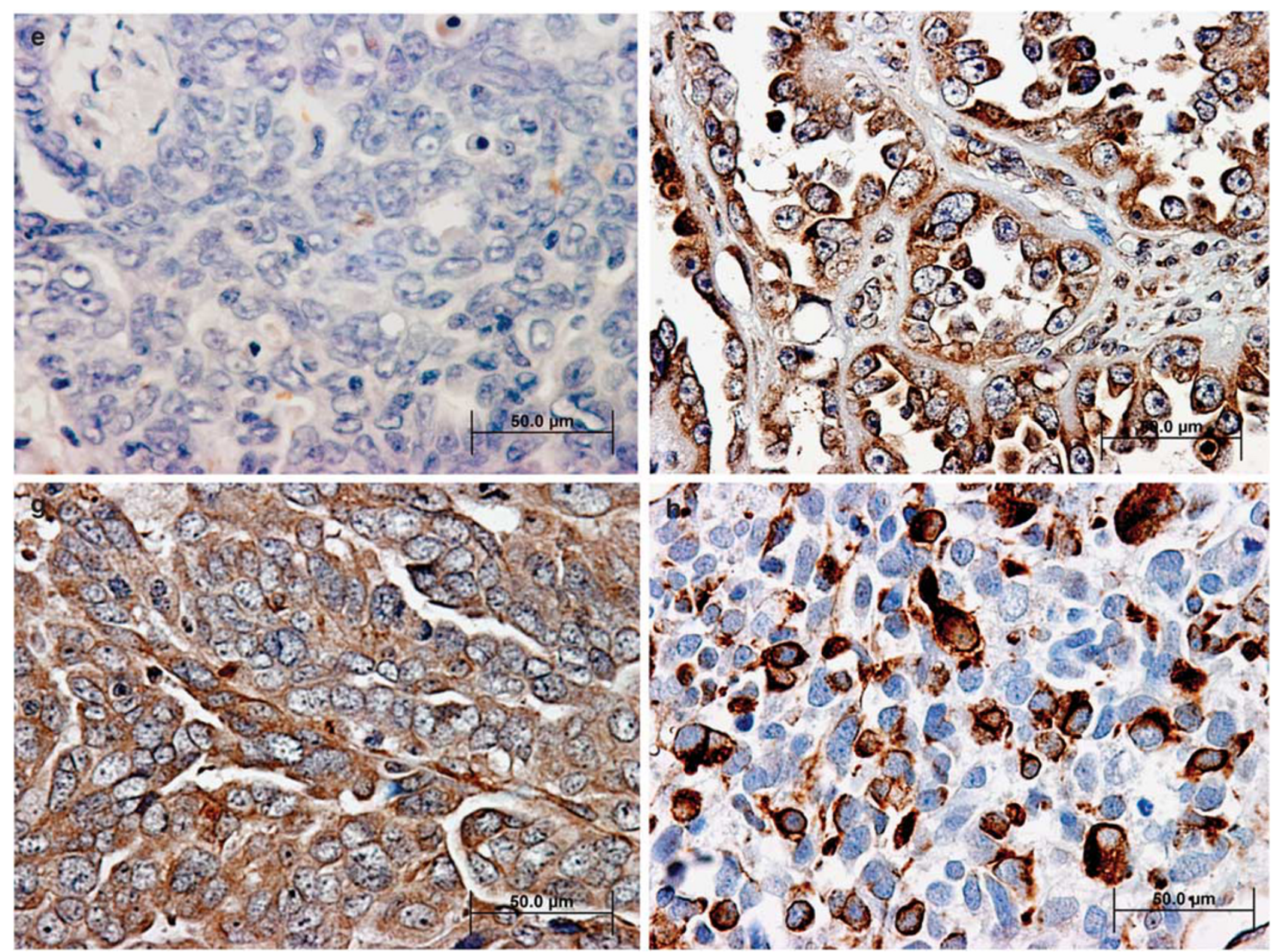

Figure 1 Continued.

lost to follow-up and were excluded from the overall survival analysis. The median overall survival time was 4.6 years (95\% confidence interval (CI): 3.9-5.2 years), and the overall survival rates were $56 \%$ (95\% CI: $53-59 \%$ ) at 3 years, $41 \%$ (95\% CI: $38-44 \%$ ) at 5 years, and $33 \%$ (95\% CI: $30-36 \%$ ) at 10 years. In all, 51 patients had no disease relapse, 165 had disease relapse, 144 had disease progression, and 40 were lost to follow-up or unknown serum CA125 level. Only the patients with and without disease relapsed were including the disease-free survival analysis. The median disease-free survival time was 1.6 years (95\% CI: $1.2-2.0$ years), and the disease-free survival rates were $32 \%$ (95\% CI: $29-35 \%$ ) at 3 years, $25 \%$ (95\% CI: $22-28 \%$ ) at 5 years, and $21 \%$ (95\% CI: $18-24 \%$ ) at 10 years.

\section{CD133 Expression and Localization}

We analyzed CD133 expression in 400 primary ovarian carcinoma samples, 15 normal fallopian tube tissue samples, 10 normal ovarian tissue samples, and 7 ovarian cystadenoma samples.
Representative samples of CD133 staining were shown in Figure 1. Staining indicated CD133positive cells in $123(31 \%)$ of 400 ovarian carcinoma tissues. Among these 123 cases, the CD133-positive distributions were sparse and scattered in $31 \%$, focal in $24 \%$, and diffuse in $45 \%$. Although CD133 has been reported to be a cell surface marker, ${ }^{7}$ in our samples a membrane staining pattern was evident in only $16 \%(20 / 123)$ of CD133-positive cases (Figure 1d). More frequently, CD133-positive cells showed moderate-to-strong, dense, brownish cytoplasmic staining (84\% (103/123) of CD133-positive cases; Figure 1f-h). CD133 immunoreactivity was also found in the cytoplasm of stromal fibroblasts.

Among the non-cancerous samples, 47\% (7/15) of normal fallopian tube, $50 \% \quad(5 / 10)$ of normal ovarian, and $14 \%(1 / 7)$ of ovarian serous cystadenoma tissue samples showed CD133 expression. In each sample, only a few cells stained positively for CD133. In contrast to CD133-positive ovarian carcinoma cells, CD133-positive epithelial cells in normal fallopian tube tissue samples (Figure 1b) showed a strong punctate or dot-like pattern in the cytoplasm. The same CD133 expression pattern was 
Table 1 Associations between CD133 expression and clinicopathologic factors

\begin{tabular}{|c|c|c|c|c|}
\hline \multirow{2}{*}{ Characteristic } & \multicolumn{3}{|c|}{ No. of patients (\%) } & \multirow[t]{2}{*}{$\mathrm{P}$-value } \\
\hline & $\begin{array}{c}\text { CD133- } \\
\text { negative } \\
\text { expressione }\end{array}$ & $\begin{array}{l}\text { CD133- } \\
\text { positive } \\
\text { expression }\end{array}$ & $\begin{array}{l}\text { Total } \\
\text { no. }\end{array}$ & \\
\hline Histologic type & & & & 0.035 \\
\hline $\begin{array}{l}\text { High-grade } \\
\text { serous carcinoma }\end{array}$ & $203(67)$ & $100(33)$ & 303 & \\
\hline $\begin{array}{l}\text { Low-grade } \\
\text { serous carcinoma }\end{array}$ & $11(73)$ & $4(27)$ & 15 & \\
\hline $\begin{array}{l}\text { Endometrioid } \\
\text { carcinoma }\end{array}$ & $29(91)$ & $3(9)$ & 32 & \\
\hline Other & $34(68)$ & $16(32)$ & 50 & \\
\hline FIGO stage & & & & $<0.001$ \\
\hline I & 30 (100) & $0(0)$ & 30 & \\
\hline II & $19(86)$ & 3 (14) & 22 & \\
\hline III & 176 (65) & 93 (35) & 269 & \\
\hline IV & $52(66)$ & $27(34)$ & 79 & \\
\hline Response to clinical treatment & & & & 0.386 \\
\hline Complete & $149(73)$ & $54(27)$ & 203 & \\
\hline Partial & $63(69)$ & $29(31)$ & 92 & \\
\hline No & $48(66)$ & $25(34)$ & 73 & \\
\hline Unknown & $17(53)$ & $15(47)$ & 32 & \\
\hline Ascites & & & & 0.010 \\
\hline No & 52 (83) & $11(17)$ & 63 & \\
\hline Yes & $166(65)$ & $89(35)$ & 255 & \\
\hline Unknown & $59(72)$ & $23(28)$ & 82 & \\
\hline Age at diagnosis & & & & 0.665 \\
\hline$\leq 60$ years & $143(70)$ & $60(30)$ & 203 & \\
\hline$>60$ years & $134(68)$ & $63(32)$ & 197 & \\
\hline CA125 & & & & 0.293 \\
\hline$<500 \mathrm{U} / \mathrm{ml}$ & 117 (73) & 44 (27) & 161 & \\
\hline$\geq 500 \mathrm{U} / \mathrm{ml}$ & $125(67)$ & $61(33)$ & 186 & \\
\hline Unknown & $35(66)$ & $18(34)$ & 53 & \\
\hline
\end{tabular}

Abbreviations: FIGO, International Federation of Gynecology and Obstetrics; CA125, cancer antigen 125 (normal range, 0-35 U/ml).

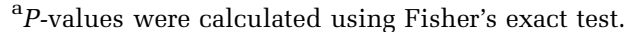

bother includes mucinous carcinoma (8 cases), clear cell carcinoma (12 cases), transitional cell carcinoma (10 cases), malignant mixed müllerian tumor (9 cases), undifferentiated carcinoma (8 cases), and mixed type carcinoma (3 cases).

observed in ovarian cystadenoma samples (Figure 1c) and in three samples of CD133-positive normal ovarian epithelial cells (Figure 1a).

\section{Association of CD133 Expression with Clinicopathologic Variables}

The results of CD133 immunohistochemical staining in the ovarian carcinoma tissue microarrays, organized according to the clinicopathologic characteristics of the patients, were summarized in Table 1. Expression of CD133 was associated with high-grade serous carcinoma $(P=0.035)$, late-stage disease $(P<0.001)$, and ascites level $(P=0.010)$. We analyzed the association of CD133 expression with the
Table 2 Associations between CD133 expression and response to chemotherapy

\begin{tabular}{|c|c|c|c|}
\hline \multirow{2}{*}{$\begin{array}{l}\text { Response to } \\
\text { chemotherapy }\end{array}$} & \multicolumn{2}{|c|}{ No. of patients (\%) } & \multirow{2}{*}{$\begin{array}{c}\text { Total } \\
\text { no. }\end{array}$} \\
\hline & $\begin{array}{c}\text { CD133- } \\
\text { negative } \\
\text { expression }\end{array}$ & $\begin{array}{c}\text { CD133- } \\
\text { positive } \\
\text { expression }\end{array}$ & \\
\hline Unknown response & $12(57)$ & $9(43)$ & 21 \\
\hline \multicolumn{4}{|l|}{ Responders $^{\mathrm{a}}$} \\
\hline \multicolumn{4}{|l|}{ Cisplatin-based regimen } \\
\hline Postsurgery ${ }^{\mathrm{b}}$ & $119(74)$ & $41(26)$ & 160 \\
\hline Presurgery & $9(90)$ & $1(10)$ & 10 \\
\hline Other regimen & $1(100)$ & $0(0)$ & 1 \\
\hline \multicolumn{4}{|l|}{ Non-responders ${ }^{\mathrm{a}}$} \\
\hline \multicolumn{4}{|l|}{ Cisplatin-based regimen } \\
\hline Postsurgery ${ }^{\mathrm{b}}$ & $83(61)$ & $53(39)$ & 136 \\
\hline Presurgery & $28(76)$ & $9(24)$ & 37 \\
\hline Other regimen & $2(67)$ & $1(33)$ & 3 \\
\hline No chemotherapy & $16(73)$ & $6(27)$ & 22 \\
\hline $\begin{array}{l}\text { Unknown chemotherapy } \\
\text { regimen }\end{array}$ & $7(70)$ & $3(30)$ & 10 \\
\hline Total & $277(69)$ & $123(31)$ & 400 \\
\hline
\end{tabular}

${ }^{\mathrm{a}}$ Responders vs non-responders: $P=0.023$.

${ }^{\mathrm{b}}$ Responders vs non-responders in cisplatin-based postsurgery subgroup: $P=0.014$.

$P$-values were calculated by one-way analysis of variance.

grade of serous or endometrioid carcinoma separately because of their different grading systems and found no association between CD133 expression and tumor grade in either serous or endometrioid carcinoma (data not shown).

The association of CD133 expression with response to chemotherapy was shown in Table 2. A total of 378 patients (95\%) were known to have received chemotherapy. Two hundred ninety-six patients $(74 \%)$ received postsurgical cisplatin-based treatment, either alone or in combination with other drugs. In 47 patients $(12 \%)$, cisplatin-based treatment was administered before debulking surgery. Four patients $(1 \%)$ received other forms of treatment (GOG182 or 5-fluorouracil plus folinic acid). Compared with the responders group and its postsurgical cisplatin-based treatment subgroup, CD133 expression was observed more often in the non-responder group than in the responder group $(P=0.023)$ and in the postsurgical cisplatin-based treatment nonresponders than in the postsurgical cisplatin-based responders $(P=0.014)$.

\section{Association of CD133 Expression with Overall Survival and Disease-Free Survival}

Overall survival and disease-free survival rates at 3, 5 , and 10 years were shown in relation to CD133 expression in Table 3. Overall, CD133 expression was associated with both overall survival and disease-free survival. Patients who had ovarian 
Table 3 Association of CD133 expression with overall and disease-free survival

\begin{tabular}{|c|c|c|c|c|}
\hline \multirow[t]{2}{*}{ CD133 status } & \multicolumn{2}{|c|}{ Overall survival $(\mathrm{n}=388)$} & \multicolumn{2}{|c|}{ Disease-free survival $(\mathrm{n}=216)$} \\
\hline & Negative & Positive & Negative & Positive \\
\hline No. of patients & 268 & 120 & 161 & 55 \\
\hline Median survival (95\% CI), years & $5.4(4.0-6.7)$ & $4.0(3.0-4.9)$ & $1.9(1.1-2.6)$ & $1.1(0.8-1.3)$ \\
\hline \multicolumn{5}{|l|}{ Survival rate (95\% CI) } \\
\hline 3 years & $0.67(0.61-0.73)$ & $0.59(0.50-0.68)$ & $0.43(0.35-0.51)$ & $0.19(0.09-0.30)$ \\
\hline 5 years & $0.50(0.44-0.57)$ & $0.37(0.28-0.47)$ & $0.33(0.25-0.40)$ & $0.12(0.03-0.21)$ \\
\hline 10 years & $0.38(0.30-0.45)$ & N/A $(<<0.23)$ & $0.27(0.20-0.35)$ & N/A $(<<0.07)$ \\
\hline$P$-value ${ }^{\text {a }}$ & \multicolumn{2}{|c|}{0.007} & \multicolumn{2}{|c|}{$<0.001$} \\
\hline
\end{tabular}

Abbreviation: CI, confidence interval.

${ }^{\mathrm{a}} P$-values were derived from the log-rank test.
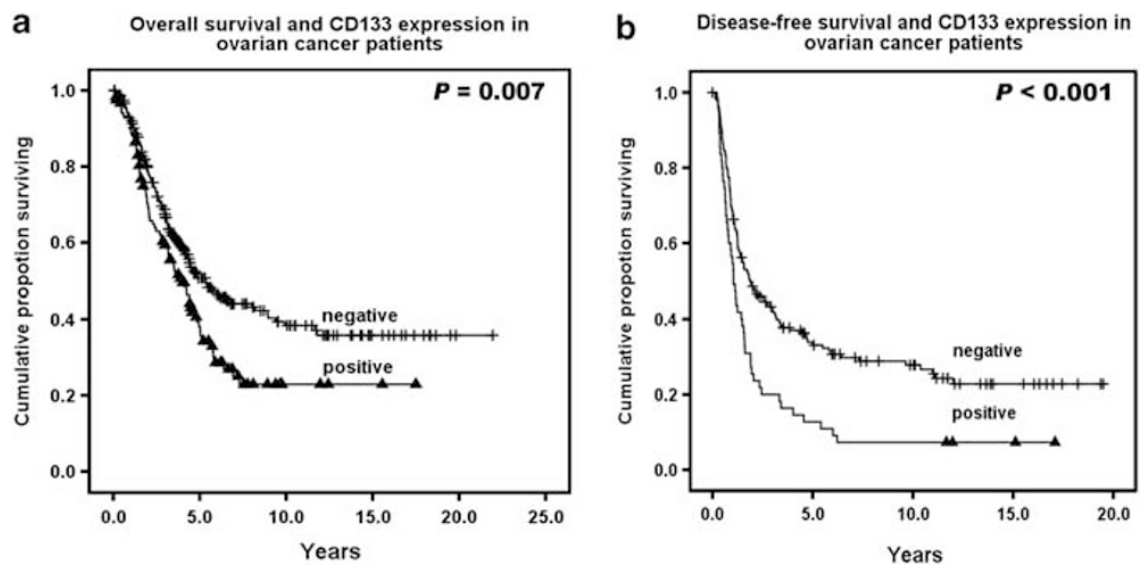

Figure 2 Kaplan-Meier survival curves for patients with ovarian carcinoma with (positive) or without (negative) CD133 expression in tumor cells: (a) overall survival $(n=388)$ and (b) disease-free survival $(n=216)$.

carcinoma with CD133 expression had shorter median overall survival $(P=0.007)$ and disease-free survival times $(P<0.001)$ than patients who had ovarian carcinoma without CD133 expression (Figure 2). There were no significant associations among the different patterns of CD133 expression (cytoplasm or membrane) and overall survival $(P=0.132)$ or disease-free survival $(P=0.880)$ or among the different degrees of CD133 expression $(<5,5-50$, or $>50 \%)$ and overall survival $(P=0.891)$ or diseasefree survival $(P=0.774)$.

Unconditional logistic regression analysis with multiple covariates revealed that CD133 status was an independent predictor of disease-free survival in patients with ovarian carcinoma (Table 4). CD133 expression was associated with shorter median disease-free survival time and higher risk increased for disease recurrence (adjusted odds ratio (OR): 1.50; $95 \%$ CI: $1.06-2.13 ; P=0.024$ ), especially in the stratified analysis according to age at diagnosis $\leq 60$ years old (adjusted OR: 2.07; 95\% CI: 1.27-3.37; $P=0.004$ ), high-grade tumor (adjusted OR: 1.51; 95\% CI: 1.06-2.16; $P=0.022$ ), complete and partial response to clinical treatment (adjusted OR: 1.53; 95\% CI: 1.08-2.18; $P=0.017$ ), and late stage (adjusted OR: $1.43 ; 95 \%$ CI: $1.00-2.05 ; P=0.048)$.
However, CD133 expression was not an independent predictor of overall survival (data not shown).

\section{Discussion}

Our results demonstrated that the CD133 expression was a predictor of poor clinical outcome in patients with ovarian cancer. CD133 expression was associated with high-grade serous carcinoma, late-stage disease, ascites level, and shorter overall survival and disease-free survival time. Moreover, multivariate logistic regression analysis showed that CD133 status was an independent predictor of disease-free survival.

Ovarian cancer has a high risk of recurrence and metastasis; tumor cells remaining after surgery often escape chemotherapy- and/or radiotherapy-induced cell death. Cancer stem cells are relatively resistant to these therapeutic methods because of abnormalities in the cell death pathway, such as inhibition of $\mathrm{NF}-\kappa \mathrm{B}$ activation, ${ }^{33}$ or overexpression of the inhibitor of apoptosis family proteins, ${ }^{34} \mathrm{Bcl}-2$ proteins, ${ }^{35}$ or TRAIL-receptor proteins. ${ }^{36}$ In our study, CD133 expression was more often observed in patients who did not respond to chemotherapy in general and 
Table 4 Multivariate analysis of the association between CD133 expression and disease-free survival $(n=214)^{\mathrm{a}}$

\begin{tabular}{|c|c|c|c|c|c|}
\hline CD133 status & $\begin{array}{c}\text { Relapse, no. of } \\
\text { patients (\%) }\end{array}$ & $\begin{array}{l}\text { No relapse, } \\
\text { no. of patients (\%) }\end{array}$ & $\begin{array}{l}\text { Odds ratio } \\
(95 \% C I)^{\mathrm{b}}\end{array}$ & $\begin{array}{c}\text { Median } \\
\text { survival, years }\end{array}$ & P-value \\
\hline Overall & & & & & 0.024 \\
\hline Negative & $47(30)$ & $112(70)$ & 1 (Reference) & 1.9 & \\
\hline Positive & $4(7)$ & $51(93)$ & $1.50(1.06-2.13)$ & 1.1 & \\
\hline Stratified by age at diagnosis ( $\leq 60$ years) & & & & & 0.004 \\
\hline Negative & $30(34)$ & $58(66)$ & 1 (Reference) & 2.9 & \\
\hline Positive & $1(3)$ & $28(97)$ & $2.07(1.27-3.37)$ & 1.1 & \\
\hline Stratified by tumor grade (high-grade) & & & & & 0.022 \\
\hline Negative & $43(29)$ & $104(71)$ & 1 (Reference) & 1.8 & \\
\hline Positive & $4(7)$ & $50(93)$ & $1.51(1.06-2.16)$ & 1.1 & \\
\hline Stratified by clinical response (complete and partial) & & & & & 0.017 \\
\hline Negative & $41(28)$ & $107(72)$ & 1 (Reference) & 1.8 & \\
\hline Positive & $3(6)$ & $48(94)$ & $1.53(1.08-2.18)$ & 1.1 & \\
\hline Stratified by FIGO stage (stage III and IV) & & & & & 0.048 \\
\hline Negative & $23(20)$ & $92(80)$ & 1 (Reference) & 1.2 & \\
\hline Positive & $3(6)$ & $51(94)$ & $1.43(1.00-2.05)$ & 1.1 & \\
\hline
\end{tabular}

Abbreviations: CI, confidence interval; FIGO, International Federation of Gynecology and Obstetrics.

${ }^{a}$ Excluding two patients unknown clinical response.

${ }^{\mathrm{b}}$ Odds ratios are adjusted for age, tumor grade, chemotherapy response, and FIGO stage.

${ }^{\mathrm{C}} P$-values were derived from unconditional logistic regression analysis with multiple covariates.

postsurgical cisplatin-based treatment in particular than in responders. These results are consistent with the hypothesis that the cells expressing CD133 are cancer stem cells and, thus, are resistant to cisplatin-based chemotherapy.

Ferrandina et $a 1^{37,38}$ were the first to identify CD133 expression in human ovarian cancer tissue. In a study of 160 cases, they found that CD133 expression seemed not to provide additional prognostic information for ovarian cancer patients. ${ }^{37,38}$ However, our study, which found an association between CD133 status and prognosis, was much larger, with 400 well-characterized patients, and included long-term patient follow-up data. Our results showing that CD133 expression is associated with various clinicopathologic characteristics of primary ovarian cancer patients, with shorter disease-free survival time, and with lack of response to chemotherapy are in agreement with findings that CD133 expression has prognostic value in hepatocellular carcinoma ${ }^{39,40}$ colon and rectal adenocarcinoma, ${ }^{41,42}$ invasive ductal breast carcinoma, ${ }^{43}$ glioma, ${ }^{44}$ and non-small cell lung carcinoma. ${ }^{45}$ Our study suggests the need to establish a novel strategy to kill CD133 + cancer cells in the future, especially in the treatment of chemoresistant or radioresistant in order to decrease disease recurrence.

There is much histologic heterogeneity in ovarian cancer. Based on clinicopathologic and genetic molecular analyses, at least a subset of ovarian high-grade serous carcinoma, ${ }^{46,47}$ may originate in the epithelium of the distal fallopian tube, although most ovarian cancers arise from various tissues of the ovaries. Therefore, we detected CD133 expression in normal ovarian and fallopian tube tissues as well as in the cancerous tumors. Only a few cells in these non-cancerous samples showed CD133 expression, and they had a strong punctate or dotlike staining pattern in the cytoplasm, which contrasted with the more diffuse staining pattern in the membrane and/or cytoplasm of the cancerous cells. This may indicate that CD133 has different locations or functions during ovarian tumorigenesis and progression, but its specific biologic mechanisms need further study.

In conclusion, CD133 expression is a predictor of poor response to chemotherapy and of reduced disease-free survival time for patients with ovarian cancer. These findings lend support to the proposed link between CD133 and cancer stem cells.

\section{Acknowledgements}

We appreciate Erica A Goodoff for her helpful editing for the paper. JL was supported by an R01 Grant (R01CA131183-01A2) and ovarian cancer Specialized Programs of Research Excellence (SPORE) Grant (IP50CA83638) from the National Institutes of Health and Ovarian Cancer Research Fund (OCRF). This work was also supported in part by the National Institutes of Health through MD Anderson's Cancer Center Support Grant (CA016672). JZ, XG, and DYC were visiting professors in Department of Pathology at MD Anderson Cancer Center.

\section{Disclosure/conflict of interest}

The authors declare no conflict of interest. 


\section{References}

1 Reya T, Morrison SJ, Clarke MF, et al. Stem cells, cancer, and cancer stem cells. Nature 2001;414:105-111.

2 O’Brien CA, Kreso A, Jamieson CH. Cancer stem cells and self-renewal. Clin Cancer Res 2010;16: 3113-3120.

$3 \mathrm{Hu}$ L, McArthur C, Jaffe RB. Ovarian cancer stem-like side-population cells are tumourigenic and chemoresistant. Br J Cancer 2010;102:1276-1283.

4 Bertrand J, Begaud-Grimaud G, Bessette B, et al. Cancer stem cells from human glioma cell line are resistant to Fas-induced apoptosis. Int J Oncol 2009;34:717-727.

5 Jemal A, Siegel R, Xu J, et al. Cancer statistics, 2010. CA Cancer J Clin 2010;60:277-300.

6 Curley MD, Garrett LA, Schorge JO, et al. Evidence for cancer stem cells contributing to the pathogenesis of ovarian cancer. Front Biosci 2011;16:368-392.

7 Miraglia S, Godfrey W, Yin AH, et al. A novel fivetransmembrane hematopoietic stem cell antigen: isolation, characterization, and molecular cloning. Blood 1997;90:5013-5021.

8 Neuzil J, Stantic M, Zobalova R, et al. Tumourinitiating cells vs. cancer 'stem' cells and CD133: what's in the name? Biochem Biophys Res Commun 2007;355:855-859.

9 Yin AH, Miraglia S, Zanjani ED, et al. AC133, a novel marker for human hematopoietic stem and progenitor cells. Blood 1997;90:5002-5012.

10 Al Dhaybi R, Sartelet H, Powell J, et al. Expression of CD133+ cancer stem cells in childhood malignant melanoma and its correlation with metastasis. Mod Pathol 2010;23:376-380.

11 Pallini R, Ricci-Vitiani L, Montano N, et al. Expression of the stem cell marker CD133 in recurrent glioblastoma and its value for prognosis. Cancer 2011;117:162174.

12 Eramo A, Lotti F, Sette G, et al. Identification and expansion of the tumorigenic lung cancer stem cell population. Cell Death Differ 2008;15:504-514.

$13 \mathrm{Ma} \mathrm{S}$, Chan KW, Hu L, et al. Identification and characterization of tumorigenic liver cancer stem/ progenitor cells. Gastroenterology 2007;132:25422556.

14 Wei C, Guomin W, Yujun L, et al. Cancer stem-like cells in human prostate carcinoma cells DU145: the seeds of the cell line? Cancer Biol Ther 2007;6: 763-768.

15 Horst D, Scheel SK, Liebmann S, et al. The cancer stem cell marker CD133 has high prognostic impact but unknown functional relevance for the metastasis of human colon cancer. J Pathol 2009;219:427-434.

16 Wright $\mathrm{MH}$, Calcagno AM, Salcido CD, et al. Brca1 breast tumors contain distinct CD44+/CD24- and CD133+ cells with cancer stem cell characteristics. Breast Cancer Res 2008;10:R10.

17 Baba T, Convery PA, Matsumura N, et al. Epigenetic regulation of CD133 and tumorigenicity of CD133+ ovarian cancer cells. Oncogene 2009;28:209-218.

18 Guo R, Wu Q, Liu F, et al. Description of the CD133+ subpopulation of the human ovarian cancer cell line OVCAR3. Oncol Rep 2010;25:141-146.

19 Curley MD, Therrien VA, Cummings CL, et al. CD133 expression defines a tumor initiating cell population in primary human ovarian cancer. Stem Cells 2009;27:2875-2883.
20 Ma L, Lai D, Liu T, et al. Cancer stem-like cells can be isolated with drug selection in human ovarian cancer cell line SKOV3. Acta Biochim Biophys Sin (Shanghai) 2010;42:593-602.

21 Scully RE. World Health Organization classification and nomenclature of ovarian cancer. Natl Cancer Inst Monogr 1975;42:5-7.

22 Russell P. The pathological assessment of ovarian neoplasms. I: introduction to the common epithelial tumours and analysis of benign epithelial tumours. Pathology 1979;11:5-26.

23 Russell P. The pathological assessment of ovarian neoplasms. II: the proliferating epithelial tumours. Pathology 1979;11:251-282.

24 Russell P. The pathological assessment of ovarian neoplasms. III: the malignant epithelial tumours. Pathology 1979;11:493-532.

25 Malpica A, Deavers MT, Lu K, et al. Grading ovarian serous carcinoma using a two-tier system. Am J Surg Pathol 2004;28:496-504.

26 Shepherd JH. Revised FIGO staging for gynaecological cancer. Br J Obstet Gynaecol 1989;96:889-892.

27 Rustin GJ, Nelstrop AE, Crawford M, et al. Phase II trial of oral altretamine for relapsed ovarian carcinoma: evaluation of defining response by serum CA125. J Clin Oncol 1997;15:172-176.

28 Armstrong DK. Relapsed ovarian cancer: challenges and management strategies for a chronic disease. Oncologist 2002;7:20-28.

29 Rustin GJ, Nelstrop AE, Tuxen MK, et al. Defining progression of ovarian carcinoma during follow-up according to CA 125: a North Thames Ovary Group Study. Ann Oncol 1996;7:361-364.

30 Rosen DG, Yang G, Deavers MT, et al. Cyclin E expression is correlated with tumor progression and predicts a poor prognosis in patients with ovarian carcinoma. Cancer 2006;106:1925-1932.

31 Sladek NE. Human aldehyde dehydrogenases: potential pathological, pharmacological, and toxicological impact. J Biochem Mol Toxicol 2003;17:7-23.

32 Chang B, Liu G, Xue F, et al. ALDH1 expression correlates with favorable prognosis in ovarian cancers. Mod Pathol 2009;22:817-823.

33 Birnie R, Bryce SD, Roome C, et al. Gene expression profiling of human prostate cancer stem cells reveals a pro-inflammatory phenotype and the importance of extracellular matrix interactions. Genome Biol 2008; 9:R83.

34 Di Fiore R, Santulli A, Ferrante RD, et al. Identification and expansion of human osteosarcoma-cancer-stem cells by long-term 3-aminobenzamide treatment. J Cell Physiol 2009;219:301-313.

35 Tagscherer KE, Fassl A, Campos B, et al. Apoptosisbased treatment of glioblastomas with ABT-737, a novel small molecule inhibitor of Bcl-2 family proteins. Oncogene 2008;27:6646-6656.

36 Sussman RT, Ricci MS, Hart LS, et al. Chemotherapyresistant sidepopulation of colon cancer cells has a higher sensitivity to TRAIL than the non-SP, a higher expression of c-Myc and TRAIL-receptor DR4. Cancer Biol Ther 2007;6:1490-1495.

37 Ferrandina G, Bonanno G, Pierelli L, et al. Expression of CD133-1 and CD133-2 in ovarian cancer. Int J Gynecol Cancer 2008;18:506-514.

38 Ferrandina G, Martinelli E, Petrillo M, et al. CD133 antigen expression in ovarian cancer. BMC Cancer 2009;9:221. 
39 Song W, Li H, Tao K, et al. Expression and clinical significance of the stem cell marker CD133 in hepatocellular carcinoma. Int J Clin Pract 2008;62:1212-1218.

40 Sasaki A, Kamiyama T, Yokoo H, et al. Cytoplasmic expression of CD133 is an important risk factor for overall survival in hepatocellular carcinoma. Oncol Rep 2010;24:537-546.

41 Li CY, Li BX, Liang Y, et al. Higher percentage of CD133+ cells is associated with poor prognosis in colon carcinoma patients with stage IIIB. J Transl Med 2009;7:56.

42 Kojima M, Ishii G, Atsumi N, et al. CD133 expression in rectal cancer after preoperative chemoradiotherapy. Cancer Sci 2010;101:906-912.

43 Zhao $\mathrm{P}$, Lu Y, Jiang X, et al. Clinicopathological significance and prognostic value of CD133 expression in triple-negative breast carcinoma. Cancer Sci 2011; 102:1107-1111.

44 Zeppernick F, Ahmadi R, Campos B, et al. Stem cell marker CD133 affects clinical outcome in glioma patients. Clin Cancer Res 2008;14:123-129.

$45 \mathrm{Xu} \mathrm{YH}$, Zhang GB, Wang JM, et al. B7-H3 and CD133 expression in non-small cell lung cancer and correlation with clinicopathologic factors and prognosis. Saudi Med J 2010;31:980-986.

46 Jarboe E, Folkins A, Nucci MR, et al. Serous carcinogenesis in the fallopian tube: a descriptive classification. Int J Gynecol Pathol 2008;27:1-9.

47 Levanon K, Crum C, Drapkin R. New insights into the pathogenesis of serous ovarian cancer and its clinical impact. J Clin Oncol 2008;26:5284-5293. 